\title{
The effect of goal setting on ability-performance relations during practice on a computerised pursuit tracking task.
}

\author{
Jennifer Waycott \& Janice Langan-Fox \\ Department of Psychology \\ The University of Melbourne \\ Parkville 3052 \\ Australia
}

\begin{abstract}
The study examined a theory proposed by Ackerman (1988) which predicts a dynamic pattern of ability-performance relations during the learning of consistent and moderately complex perceptual motor tasks. The theory is particularly relevant for explaining the development of automatisation at computerised tasks. In the present investigation, one group of participants were given a specific and difficult performance goal while another group was simply told to "do your best". All participants were then given 32 trials on a computerised pursuit tracking task, with performance scores on this task then correlated with ability scores. It was expected that the goal-setting manipulation would disrupt the normal pattern of ability-performance correlations. Although some group differences were found, overall the results failed to support Ackerman's theory. Thus, Ackerman's model may be theoretically underdeveloped and further investigation, including consideration of the effect of goal setting, is required to fully understand the relationship between abilities and performance on computerised tasks.
\end{abstract}

KEY WORDS: Skill acquisition, individual differences, cognitive models, ability, performance.

\section{INTRODUCTION}

This study examined how the assignment of a performance goal moderates the relationship between abilities and performance during the learning of a computerised pursuit tracking task. Specifically, the investigation was designed to test Ackerman's (1988) theory of ability-performance relations during skill acquisition. Ackerman's theory predicts a dynamic pattern of ability-performance relations during practice on consistent and moderately complex perceptual motor tasks. Therefore, the theory can be applied to skills involved in operating computerised tasks, which generally have consistent information-processing requirements, and are increasingly being utilised by employees in various occupational settings.

\subsection{Ackerman's (1988) theory}

Ackerman (1988) proposed that three broad classes of ability - general ability, perceptual speed ability, and psychomotor ability - determine performance as practice progresses through the three phases of skill acquisition, described by informationprocessing theories of learning (e.g., Anderson, 1976, 1987; Fitts \& Posner, 1967; Schneider \& Shiffrin, 1977). The three skill acquisition phases mapped to the abilities proposed by Ackerman, are outlined in the table below. 


\begin{tabular}{|l|l|}
\hline \multicolumn{1}{|c|}{ SKILL ACQUISITION PHASE } & ABILITY CLASSES \\
\hline PHASE 1: & General ability: \\
Performance is slow, error-prone and requires & $\begin{array}{l}\text { Represents a broad construct that underlies non- } \\
\text { specific information-processing efficacy. } \\
\text { conscious control. }\end{array}$ \\
eg: reasoning processes.
\end{tabular}

Table 1. Ackerman's (1988) theory of ability-performance relations during skill acquisition.

The basic rationale behind Ackerman's (1988) theory is that as performance progresses from controlled processing (Phase 1) to automatic processing (Phase 3), the resources required by a task change. Correspondingly, the abilities determining performance also change. Initial individual differences in performance will be determined by general cognitive ability. Then, as the resourcedependency of performance is reduced (i.e., Phase 2), perceptual speed ability will primarily determine performance variability. Finally, when automaticity is reached (i.e., Phase 3), performance is said to correspond to predominantly noncognitive psychomotor abilities. Figure 1 (right) depicts the predicted pattern of abilityperformance correlations across the three phases of learning.

\subsection{The study}

The current investigation aimed to examine how the setting of a specific and difficult performance goal might moderate the pattern of ability-performance correlations proposed by Ackerman (1988). Participants (60 first year psychology students at the University of Melbourne)

were given 32 trials on a highly consistent computerised pursuit tracking task. The task involved following a target box moving horizontally across the screen with a cursor controlled by the computer mouse. The mouse controls were reversed, such that moving the mouse in one direction resulted in the cursor moving in the opposite direction across the screen. At the end of each 45-second trial a performance score (the percentage of time spent on target) was given. One group of participants $(n=31)$ were told that they must try to reach a score of $70 \%$ by the end of the session. The remaining participants $(n=29)$ were simply told to "do your best". Scores on each practice trial were correlated with three composite ability scores, obtained from the administration of nine ability tests which were previously used by Ackerman (1988) and were factor analysed to ensure each test loaded on the appropriate ability class.

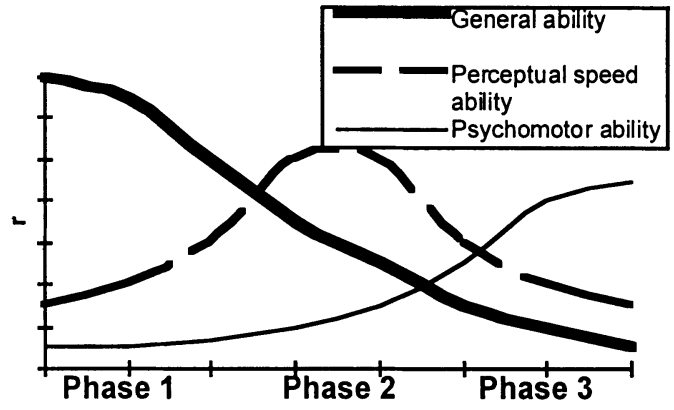

Figure 1. Ability-performance correlations proposed by Ackerman

\section{HYPOTHESES}

It was expected that, because motivational forces are said to interfere with the attentional resources available for on-task attention (Kanfer \& Ackerman, 1989, 1996), the goal-setting manipulation would slow, or even preclude the progression of skill acquisition through the three learning phases. Therefore, it was predicted that the ability-performance correlations for individuals given a performance goal would depart from the pattern predicted by Ackerman, such that:

1. General ability-performance correlations would decrease later in task practice;

2. Perceptual speed ability-performance correlations would increase later in task practice;

3. Psychomotor ability-performance correlations would remain low throughout the practice session.

\section{RESULTS \& DISCUSSION}

Curve estimates of the ability-performance correlations plotted against trial number, were obtained using linear regression for general and psychomotor 
abilities, and cubic regression for perceptual speed ability.

In contrast to predictions, there were no significant between-group differences for the pattern of general and perceptual speed ability-performance correlations. Thus, there was no support for the hypothesis that there would be a disruption in the normal process of abilityperformance correlations for subjects in the goal condition. The prediction that there would be little evidence of the influence of psychomotor ability on performance was partially supported. For subjects who were given a performance goal, the psychomotor abilityperformance correlations were actually negative, in comparison to the positive correlations for the no-goal group. This would suggest that, as expected, the goal manipulation precluded the development of Phase 3 (psychomotor) performance. Nevertheless, the psychomotor ability-performance correlations decreased, rather than increased across practice, suggesting that Ackerman's (1988) proposal that psychomotor ability is associated with performance during Phase 3 of skill acquisition may be inaccurate. Alternatively, it is possible that participants in both groups did not proceed past Phase 1 of skill acquisition, given that general ability-performance correlations remained high across task practice. This means that further practice trials would be necessary to examine the effect of goal setting on ability-performance correlations as automatisation at a computerised task develops.

On all three ability measures (i.e., general, perceptual speed, and psychomotor abilities), the correlations with performance exhibited quite substantial instability from trial to trial for subjects in both the goal and no-goal conditions. Thus, the correlations did not generally follow the pattern that Ackerman's (1988) theory predicted. It is possible that the computer game-like qualities of the pursuit tracking task may have tapped different abilities than those identified by Ackerman, and that the dynamic spatial qualities of the pursuit tracking task differed substantially from the reaction time tasks used in Ackerman's (1988) study. Nevertheless, the results do suggest that Ackerman's theory may have several flaws; for example, the ability classes he identified and mapped onto the phases of skill acquisition appear to be inaccurate.

\section{CONCLUSION}

It is apparent that motivational variables may moderate the relationship between abilities and performance, and the effect of goal setting on abilityperformance relations during practice on computerised tasks, needs further examination. It may also be beneficial for future research to consider the interactive effects of goal setting and dispositional constructs. Such research could have important implications for industrial training, particularly with respect to consistent and repetitive computerised tasks which are becoming increasingly common in contemporary workplaces.

\section{REFERENCES}

Ackerman, P. L. (1988). Determinants of individual differences during skill acquisition: Cognitive abilities and information pocessing. Journal of Experimental Psychology: General, 117, 288-318.

Anderson, J. R. (1976). Language, Memory and Thought. NJ: Lawrence Erlbaum.

Anderson, J. R. (1987). Skill acquisition: compilation of weak-method problem solutions. Psychological Review, 94, 192-210.

Fitts, P. M. \& Posner, M. I. (1967). Human Performance. Belmont: Brooks/Cole Publishing Company.

Kanfer, R. \& Ackerman, P. L. (1989). Motivation and cognitive abilities: An integrative/aptitude-treatment interaction approach to skill acquisition [monograph]. Journal of Applied Psychology, 74, 657-690.

Kanfer, R. \& Ackerman, P. L. (1996). A selfregulatory skills perspective to reducing cognitive interference. In I. G. Sarason, G. R. Pierce, \& B. R. Sarason (Eds.) Cognitive Interference: Theories, Methods, and Findings (pp 153-171). Mahwah, NJ: Lawrence Erlbaum Associates.

Schneider, W. \& Shiffrin, R. M. (1977). Controlled and automatic human information processing: I. Detection, search, and attention. Psychological Review, 84, 127-190. 